\title{
The combined effects of the ENSO and the Arctic Oscillation on the winter climate anomalies in East Asia
}

\author{
CHEN Wen*, LAN XiaoQing, WANG Lin \& MA Yin \\ Center for Monsoon System Research, Institute of Atmospheric Physics, Chinese Academy of Sciences, Beijing 100190, China
}

Received October 26, 2012; accepted December 11, 2012; published online January 31, 2013

\begin{abstract}
With the warm/cold phases of the El Niño and Southern Oscillation (ENSO) as a background, the impacts of monthly variation in the Arctic Oscillation (AO) on the winter climate anomalies in East Asia are studied with the NCEP/DOE Reanalysis 2 data and the Chinese station data regarding temperature and rainfall. The combined effects of ENSO and the AO indicate that the winter climate anomalies are mainly influenced by the AO in northern China and the ENSO in southern China, when an El Niño couples with a negative $\mathrm{AO}$ month or a La Niña couples with a positive $\mathrm{AO}$ month. These climate anomalies in China are consistent with the mechanisms proposed in previous studies. However, most of China presents a different pattern of climate anomalies if an El Niño couples with a positive AO month or a La Niña couples with a negative AO month, with the exception of the temperature anomalies in northern China, which are still affected dominantly by the AO. Further analysis suggests that the causes are attributed to the differences in both the stratosphere-troposphere interaction and the extratropics-tropics interaction. In the former cases, zonal symmetric circulation prevails in the winter and the extratropics-tropics interaction is weakened. Thus, the influences of the ENSO and the AO on the East Asian climate mainly present linear combination effects. On the contrary, an annular mode of atmospheric circulation is not favored in the latter cases and the extratropics-tropics interaction is strong. Hence, the combined effects of the ENSO and the AO on the winter climate in East Asia present nonlinear characteristics.
\end{abstract}

ENSO, AO, winter climate in East Asia, temperature and rainfall anomalies, stratosphere-troposphere interaction

Citation: Chen W, Lan X Q, Wang L, et al. The combined effects of the ENSO and the Arctic Oscillation on the winter climate anomalies in East Asia. Chin Sci Bull, 2013, 58: 1355-1362, doi: 10.1007/s11434-012-5654-5

The East Asian winter climate is mainly influenced by the East Asia Winter Monsoon (EAWM) [1-3]. The major features of EAWM include the Siberian high over the Eurasian continent, the Aleutian low over North Pacific and strong northwesterlies along the eastern flank of the Siberian high. These winds split into two branches over southern Japan. One branch blows eastward to the subtropical western to central Pacific and the other blows along the coast of East Asia and reaches the South China Sea [4]. There is an East Asian Trough centered at the longitudes of Japan in the middle troposphere and an East Asian Jet in the upper troposphere, which are linked with strong baroclinic instability and cold air advection [5-7]. Anomalous EAWM can lead to persistent cooling, snow storms and frozen disasters,

*Corresponding author (email: cw@post.iap.ac.cn) which may cause heavy casualties and severe economic losses. Therefore, it is crucial to understand the variability mechanism of the EAWM [8,9].

Many studies have focused on the relationship between the EAWM and the El Niño and Southern Oscillation (ENSO), which is a dominate mode of the tropical Pacific airsea coupling system on an interannual timescale [10]. For example, an anomalous anticyclonic circulation is maintained over the northwestern Pacific during a warm phase of ENSO, which may induce a weaker EAWM with a higher temperature in East Asia and more rainfall over the southern part of China [11-14]. Recently, several studies have found that the Arctic Oscillation (AO) significantly affects the East Asian winter climate [15-19]. The AO is a prominent mode of low frequency variability in the extratropical northern hemisphere, which features an out-of-phase oscillation in 
sea level pressure between the polar region and the midlatitudes [20,21]. The EAWM becomes weaker with warm anomalies in northeastern and northern China during a positive phase of AO [22,23]. So far, how the AO influences the East Asian climate is still an open question. Gong et al. [15] suggested that the AO could influence the EAWM via the Siberian High. Wu and Wang [16] believed that the AO can influence the EAWM directly. Chen et al. indicated an important role for planetary waves in the AO's influence $[18,24]$. In fact, the ENSO and the AO are believed to be the two important factors influencing the strength of the EAWM based on a study of the current EAWM indices [25].

However, all previous research has documented the individual impact of the ENSO or AO. Their combined effects may be different compared to an individual effect. For example, the AO anomaly with a La Niña event was shown to be responsible for the frozen rain and snow storm disaster in southern China during January 2008 [26]. Additionally, in the 2009/2010 winter, the extremely negative AO was suggested as the main cause for the extremely low temperature and snow storm in northern China, while the ENSO was thought to have played a secondary role [27]. Therefore, it is necessary to consider both the ENSO and the AO in studying the East Asian winter climate variability. This paper is organized as follows: the data and methods are introduced first, after which the winter temperature and precipitation anomalies in East Asia under different combinations of ENSO and AO phases are analyzed. A summary is given after a discussion of possible mechanisms.

\section{Data and methodology}

In this study, the NCEP/DOE Reanalysis 2 dataset from the National Centers for Environmental Prediction (NCEP) and the Department of Energy (DOE) and the monthly temperature and precipitation of 160 stations of China from the China Meteorological Administration (CMA) are used. The NCEP/DOE Reanalysis 2 dataset has a $2.5^{\circ} \times 2.5^{\circ}$ spatial resolution, contains data beginning from 1979 and has 17 vertical pressure levels extending from 1000 to $10 \mathrm{hPa}$, which is an improvement of the NCEP/NCAR (The National Center for Atmospheric Research) reanalysis data. Some known mistakes and bugs have been fixed, and some physical parameterizations have been optimized in the improved version [28]. The monthly AO and the Niño 3 index can be downloaded from the National Oceanic and Atmospheric Administration (NOAA) website (http://www.cpc.ncep.noaa. gov).

Considering that an El Niño or La Niña event has a longer life cycle, while the AO has a higher frequency variability and could change intensely during one winter, the monthly anomalies of 31 winters from 1979/1980 to 2009/2010 are taken into consideration in this study. An El Niño (or a La
Niña) winter is identified if the DJF mean Niño 3 index exceeds \pm 0.7 standard deviation. Hence, we obtained $7 \mathrm{El}$ Niño and $8 \mathrm{La}$ Niña winters. We considered a winter to be from November of the previous year to March of the current year. The five months of every winter are divided into 4 groups of anomalous months according to the monthly $\mathrm{AO}$ index that exceeds \pm 0.75 standard deviation and the El Niño or La Niña event. The winter is defined as by the NDJFM instead of the DJF so that we could obtain a sufficient numbers of cases. The anomalous months selected are listed in Table 1. A composite analysis is employed to different groups based on the phases of the ENSO and the AO, and Student's $t$-test is used to examine the significance level. A monthly anomaly is capable of depicting the high frequency variability of the AO to avoid the information loss by seasonal mean; on the other hand, it is helpful in obtaining larger sample numbers and is consistent with the hypothesis of the statistical test.

\section{The combined effects of the ENSO and the AO}

The EAWM is cold and dry due to the cold air from the north. Figure 1 depicts the composite $850 \mathrm{hPa}$ temperature anomaly in the months for different phases of the AO during an El Niño or La Niña winter. During an El Niño winter, a positive temperature anomaly appears in the South China Sea, South China, the eastern coast area and eastern Japan with statistical significance (Figure 1(c)). However, during a La Niña winter, the temperature anomaly in China is weak and not significant (Figure 1(f)). Obviously, the relationship between the warm (cold) phases of the ENSO with higher (lower) temperature in East Asia fails after taking the AO into consideration. The temperature anomaly pattern is characterized by a south-north dipole (Figure 1). During an El Niño winter, a positive temperature anomaly above $2^{\circ} \mathrm{C}$ is located in Siberia north of $45^{\circ} \mathrm{N}$ and a weak negative temperature anomaly appears in the central part of China in the months with a positive AO (Figure 1(a)). In contrast, in the months with a negative $\mathrm{AO}$, there are negative temperature

Table 1 The selected anomalous months based on the Niño 3 and AO indices

\begin{tabular}{|c|c|c|}
\hline & Positive AO & Negative AO \\
\hline \multirow[b]{2}{*}{$\begin{array}{l}\text { El Niño } \\
\text { winters }\end{array}$} & 10 & 11 \\
\hline & $\begin{array}{l}\text { 1982-12, 1983-01, 1986-11, } \\
\text { 1991-12, 1992-02, 1992-03, } \\
\text { 2003-03, 2006-12, 2007-01, } \\
\text { 2007-03 }\end{array}$ & $\begin{array}{c}1983-02,1987-01,1987-02, \\
1987-03,1998-01,2002-11, \\
2002-12,2007-02,2009-12, \\
2010-01,2010-02\end{array}$ \\
\hline \multirow[b]{2}{*}{$\begin{array}{l}\text { La Niña } \\
\text { winters }\end{array}$} & 13 & 11 \\
\hline & $\begin{array}{l}\text { 1988-12, 1989-01, 1989-02, } \\
\text { 1989-03, 1997-02, 1997-03, } \\
\text { 1998-12, 1999-12, 2000-01, } \\
\text { 2000-02, 2007-12, 2008-01, } \\
\text { 2008-02 }\end{array}$ & $\begin{array}{c}\text { 1984-11, 1985-01, 1985-02, } \\
\text { 1995-12, 1996-01, 1996-03, } \\
\text { 1996-12, 1998-11, 1999-03, } \\
2005-12,2006-03\end{array}$ \\
\hline
\end{tabular}



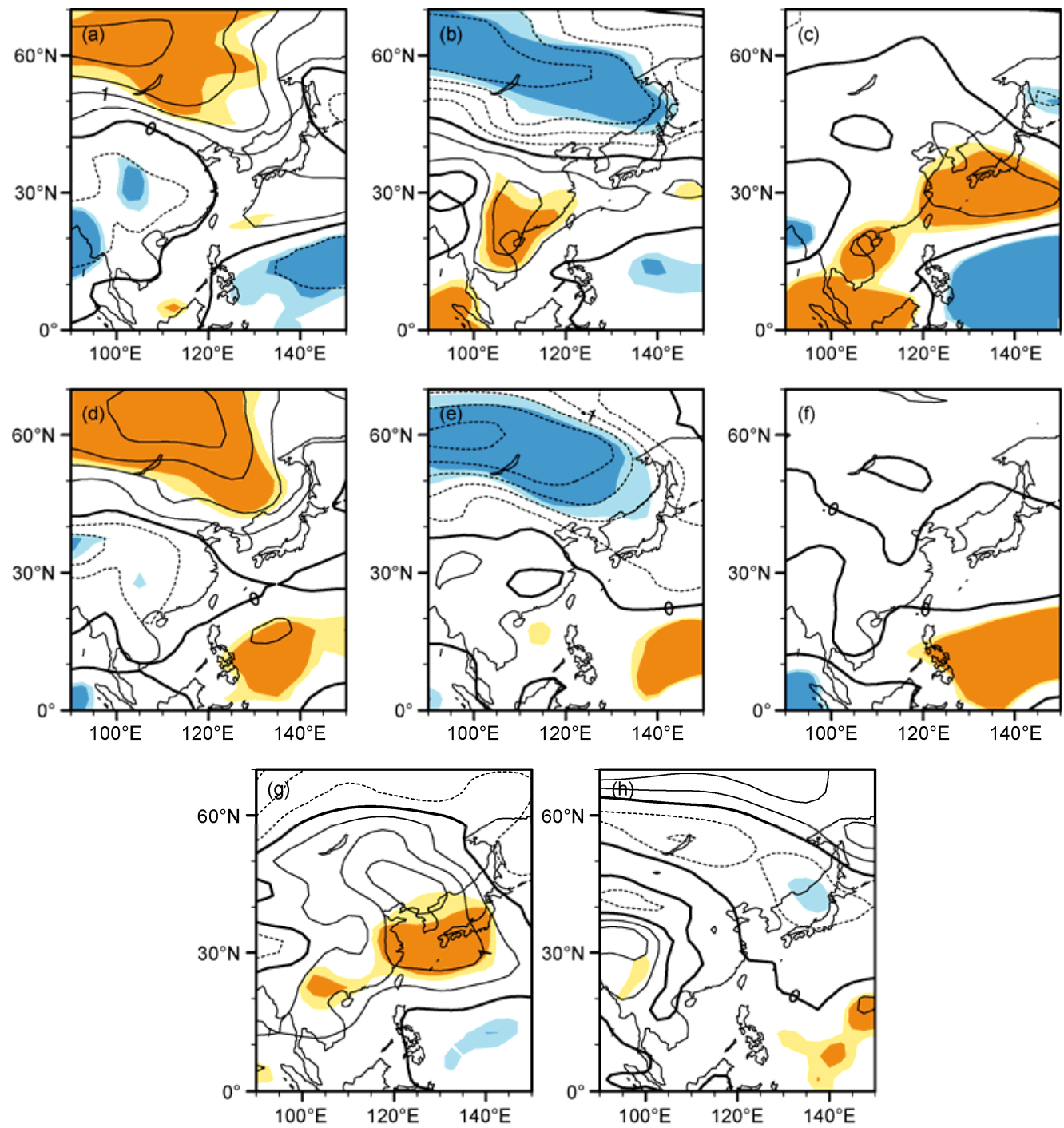

Figure 1 Monthly composite $850 \mathrm{hPa}$ temperature anomaly in East Asian. (a) Positive AO months during the El Niño winter; (b) negative AO months during the El Niño winter; (c) all months during the El Niño winter; (d) positive AO months during the La Niña winter; (e) negative AO months during the La Niña winter; (f) all months during the La Niña winter; (g) obscure AO months during the El Niño winter; (h) obscure AO months during the La Niña winter. The contour interval is $0.5^{\circ} \mathrm{C}$. The negative values are dashed, and dark (light) shading indicates the $95 \%$ (90\%) confidence level.

anomalies lower than $-2^{\circ} \mathrm{C}$ in Siberia and significant warming above $1^{\circ} \mathrm{C}$ in the southern part of China (Figure 1(b)). The temperature anomalies mentioned before in both cases are statistically significant. Similarly, when a La Niña event couples with a positive AO month, there is a warm anomaly above $2^{\circ} \mathrm{C}$ in Siberia and a weakened cold anomaly in the central part of China (Figure 1(d)). When a La Niña event couples with a negative AO month, there is a significant cold anomaly in Siberia, while the temperature anomaly in the southern part of China is obscure and weak (Figure 1(e)). Therefore, the distribution of temperature anomalies in East Asia strongly depends on the phases of both the ENSO and the AO. In addition, the composite results for the months without an anomalous AO during the El Niño and La Niña winters (Figure $1(\mathrm{~g})$ and (h)) reveal that the AO has a significant impact on the relationship between the ENSO and the winter climate in China.

The results from the reanalysis data can be confirmed with the temperature data from 160 stations in China. The major feature of winter temperature in China is the dipole pattern between the north and south among different phase configurations of the ENSO and AO (Figure 2). The dipole pattern with warmth in the north and cold in the south is found when an El Niño event couples with a positive AO month (Figure 2(a)) and a La Niña event couples with a positive AO month (Figure 2(c)). The dipole pattern is reversed when an El Niño event couples with a negative AO month (Figure 2(b)). However, the temperature anomaly is different from others with a mainly cold anomaly pattern when a La Niña event couples with a negative AO month (Figure 2(d)). Hence, the temperature anomaly in northern China (north of $40^{\circ} \mathrm{N}$ ) is dominated by the $\mathrm{AO}$ and it becomes 

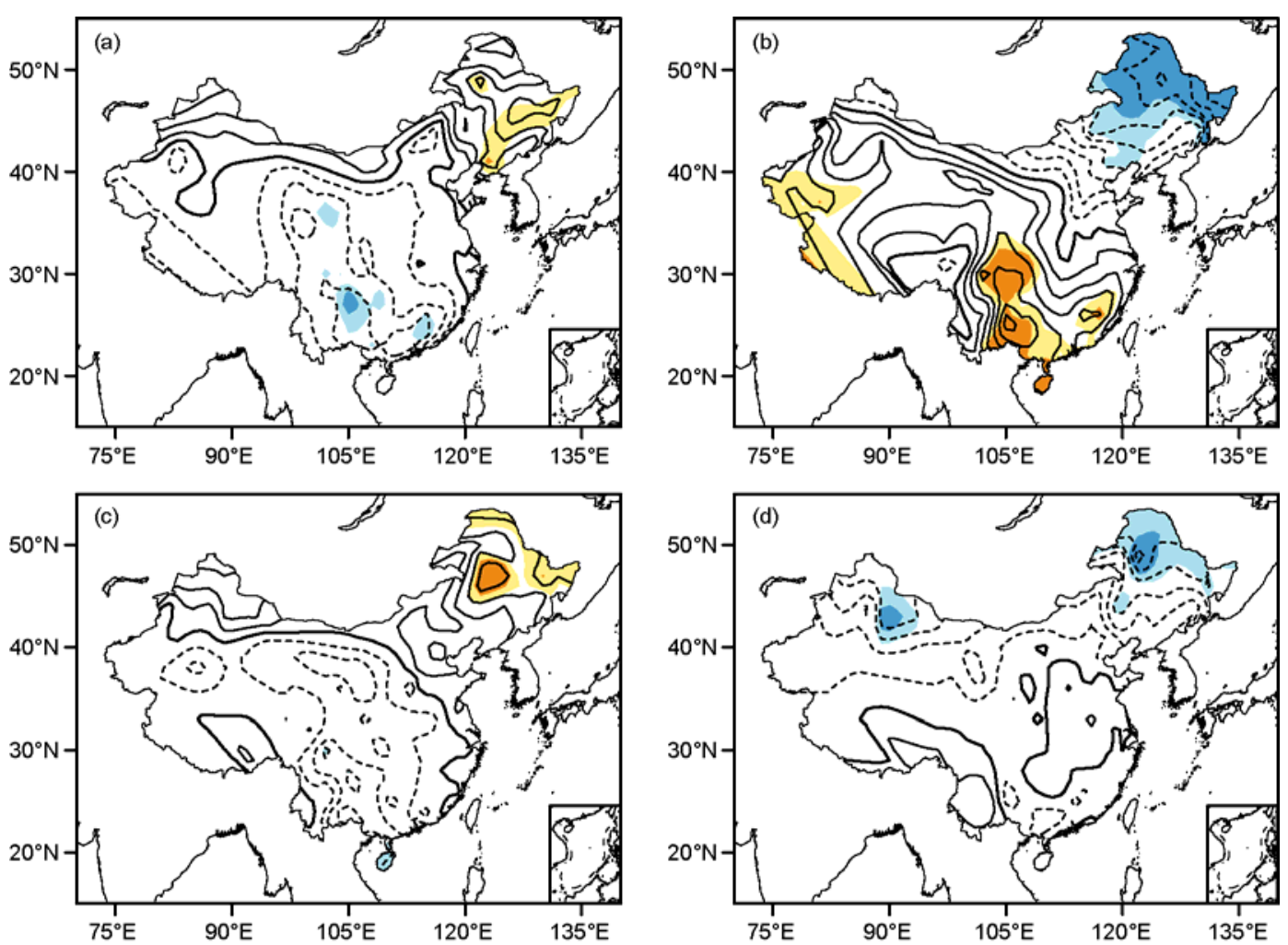

Figure 2 Monthly composite temperature anomaly of 160 stations in China. (a) Positive AO months during the El Niño winter; (b) negative AO months during the El Niño winter; (c) positive AO months during the La Niña winter; (d) negative AO months during the La Niña winter. The contour interval is $0.25^{\circ} \mathrm{C}$. The negative values are dashed, and dark (light) shading indicates the $95 \%(90 \%)$ confidence level.

warmer in the months with a positive $\mathrm{AO}$ and vice versa. However, the temperature anomaly in the southern and western parts of China does not completely depend on the phase of the ENSO. The phase of the AO seems to interrupt the relationship between the ENSO and the EAWM. The results indicate that southern China gets colder instead of warmer in the months with a positive AO, even during an El Niño winter (Figure 2(a)), and no significant cold anomaly can be observed in the months with a negative $\mathrm{AO}$, even during a La Niña winter (Figure 2(d)).

Previous studies show that winter precipitation mainly occurs south of the Yangtze River [18]. Additionally, some works indicate that the ENSO has an essential impact on the winter precipitation in South China [29-31]. The distribution of the monthly precipitation anomaly in different $\mathrm{AO}$ phases during the El Niño and La Niña winters based on the 160 station data in China is illustrated in Figure 3. The strongest precipitation anomaly is clearly shown south of the Yangtze River. South China and the southeast coast area obtain more rainfall during the El Niño winter (Figure 3(a) and (b)), while, during the La Niña winter, South China and the southeast coast area become drier in the months with a positive AO (Figure 3(c)) and wetter in the months with a negative AO (Figure 3(d)). In the latter cases, the area with less rainfall appears in the north to the Yangtze River valley. It should be noted that the statistical significance for the precipitation anomaly is not high. This low significance may be due to the large regional differences in precipitation. For example, the large negative precipitation anomalies appear in the middle and lower reaches of the Yangtze River. Because the standard deviation of precipitation in this area is large, the negative precipitation anomalies cannot reach a high significance level. Therefore, we can conclude that, similar to temperature, the relationship between the ENSO and the winter precipitation in southern China exists when an El Niño winter couples with a negative AO month or a La Niña winter couples with a positive AO month. Additionally, the anomalous precipitation pattern is almost opposite in these two cases (Figure 3(b) and (c)). However, the precipitation anomalies behave nonlinearly when an El Niño winter couples with a positive AO month or a La Niña winter couples with a negative AO month (Figure 3(a) and (d)). Especially in the latter case, the relationship between the ENSO and the winter precipitation in southern China does not follow the conventional one.

\section{Possible mechanism}

How can different phases of the ENSO background and the AO anomalous months result in such different climate anomaly patterns in East Asia? Previous studies show that 

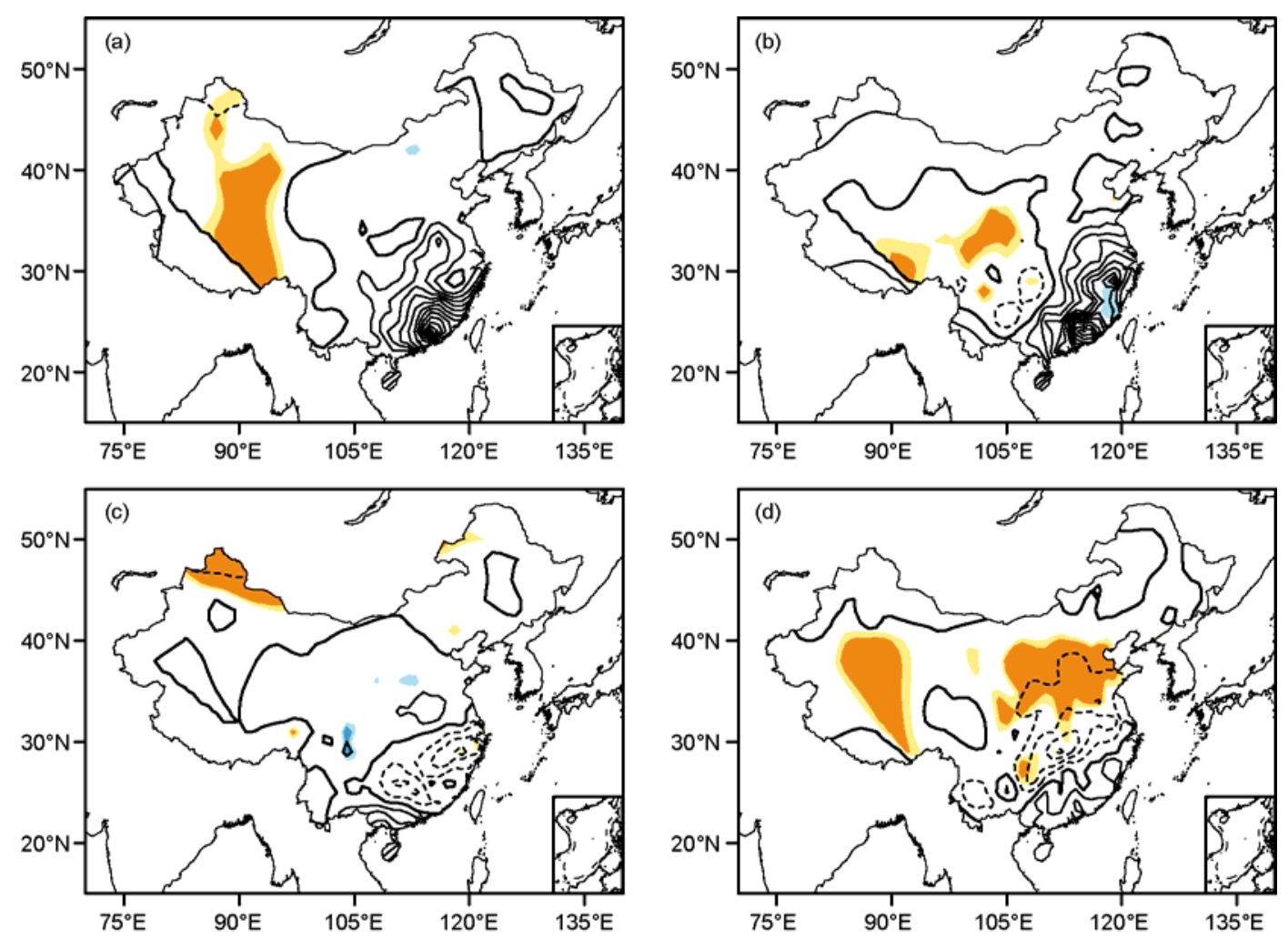

Figure 3 Monthly composite precipitation anomaly of 160 stations in China. (a) Positive AO months during the El Niño winter; (b) negative AO months during the El Niño winter; (c) positive AO months during the La Niña winter; (d) negative AO months during the La Niña winter. The contour interval is 5 $\mathrm{mm} / \mathrm{month}$. The negative values are dashed, and dark (light) shading indicates the $95 \%$ (90\%) confidence level.

during an El Niño (or a La Niña) winter, an anticyclonic (a cyclonic) circulation is maintained over the west Pacific and the associated southerly (northerly) anomalies lead to warmer (colder) winters in China [12,13]. The regression of $850 \mathrm{hPa}$ wind onto the Niño 3 index clearly exhibits the western Pacific anticyclone (Figure 4(a)) and confirms that the winter climate anomalies in East Asia are strongly influenced by the ENSO. The link between the AO and the winter climate anomaly in East Asia has also been well analyzed. Figure 4(b) illustrates the linear regression of the winter mean zonal winds at $200 \mathrm{hPa}$ onto the AO index. Apparently, a positive AO coincides with a weaker East Asian Jet and baroclinicity, less cold air break, and warmer temperatures in the northern part of China. The reverse is true for a negative AO. The winter temperature and precipitation anomalies in China can be well explained by a linear superposition of the impacts of the ENSO and the AO on the EAWM when an El Niño event couples with a negative AO month or a La Niña event couples with a positive AO month. However, it does not help when an El Niño event couples with a positive AO month or a La Niña event couples with a negative AO month.

Figure 5 describes the composite monthly $500 \mathrm{hPa}$ geopotential height anomalies and their zonal averages in different phases of the AO during the El Niño or La Niña winters. The distribution of anomalous geopotential height in middle latitudes (approximately $45^{\circ} \mathrm{N}$ ), as shown in Figure 5(b) and (c), is more zonally symmetric when a negative AO month coincides with an El Niño winter or a positive AO month coincides with a La Niña winter, which indicates weakened mid-latitude disturbances. Meanwhile, the opposite sign of zonal mean geopotential height anomaly in the middle latitudes and the tropical region indicates a weaker interaction between the middle-low latitudes. Hence, the influence from the tropics (mid-high latitudes) can hardly reach the mid-high latitudes (tropics), and the effects of the ENSO, which dominates the southern part of China, and the AO, which affects the northern part of China, are linearly superimposed over East Asia. However, the zonal symmetry of the geopotential height anomaly in the middle latitudes (approximately $45^{\circ} \mathrm{N}$ ) significantly decreases when a positive AO month coincides with an El Niño winter or a negative AO month coincides with a La Niña winter (Figure 5(a) and (d)). The positive and negative anomalies of geopotential height are distributed alternately, indicating stronger disturbances with more wave-like circulation in the middle latitudes. Particularly, an anomalous geopotential height over East Asia extends to the tropical region with same sign and the zonal average of geopotential height does the same (Figure 5(a) and (d)). Both of these observations show that there are strong interactions between the middle and low latitudes. Consequently, the influences of the ENSO and the 

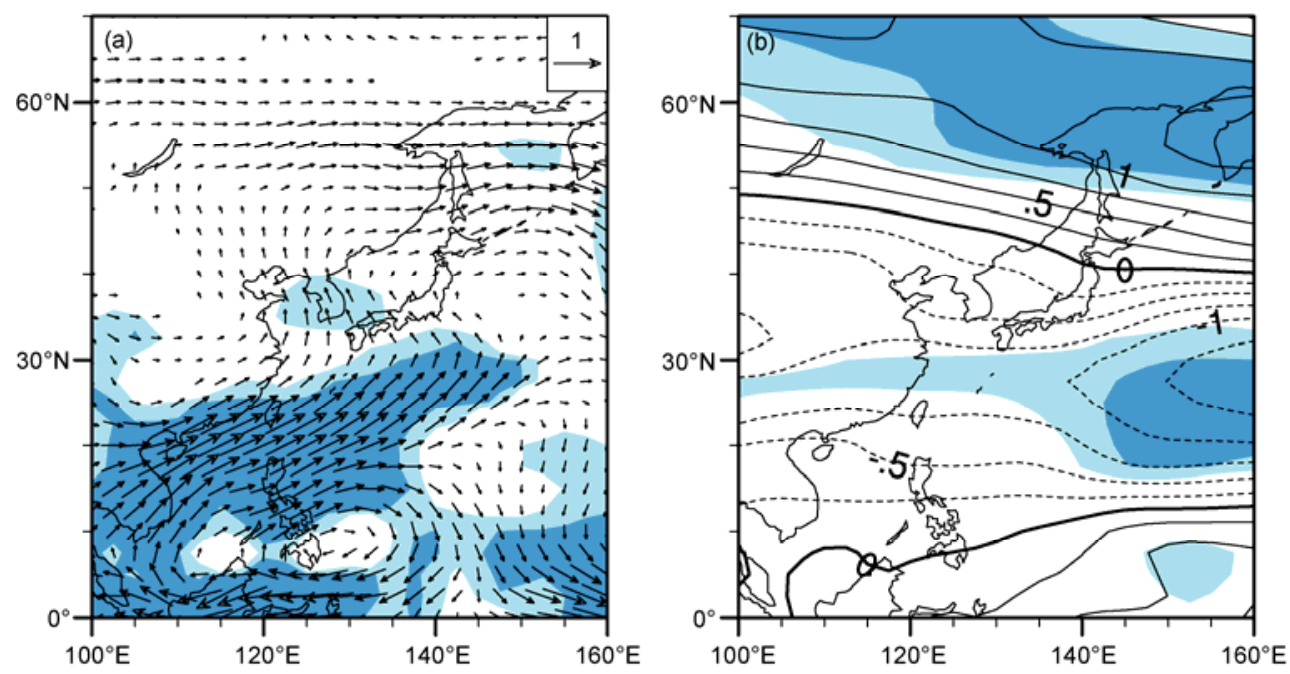

Figure 4 (a) Regression pattern of the winter mean $850 \mathrm{hPa}$ winds onto the Niño 3 index (Unit: $\mathrm{m} / \mathrm{s}$ ); (b) regression pattern of the winter mean $200 \mathrm{hPa}$ winds onto the AO index. The contour interval is $0.25 \mathrm{~m} / \mathrm{s}$, and dark (light) shading indicates the $95 \%$ (90\%) confidence level.
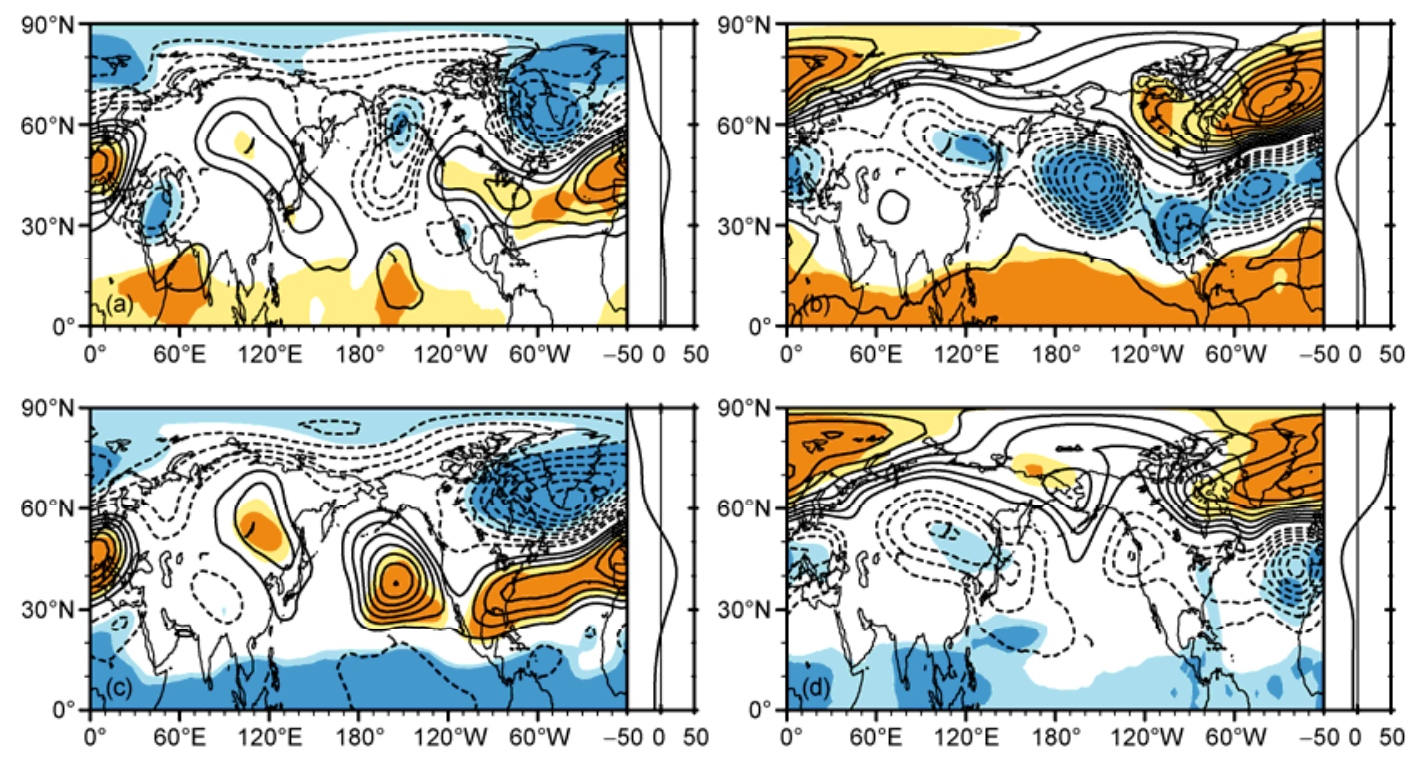

Figure 5 Monthly composite of 500 Pa geopotential height anomalies in the Northern Hemisphere during winter and their zonal averages. (a) In the positive AO months during an El Niño winter; (b) in the negative AO months during an El Niño winter; (c) in the positive AO months during a La Niña winter; (d) in the negative AO months during a La Niña winter. The contour interval is $10 \mathrm{gpm}$ and the zero line is suppressed. The negative values are dashed, and dark (light) shading indicates the $95 \%$ (90\%) confidence level.

$\mathrm{AO}$ on the East Asian winter climate interact with each other and have a nonlinear combination effect. These effects result in an anomalous pattern different from that shown in Figure 5(b) and (c). Therefore, when a positive AO month couples with an El Niño winter, northern China is anomalously warm due to the AO, while southern China is not dominated by the El Niño event but is cold. When a negative AO month couples with a La Niña winter, the condition of northern China does not change but the temperature anomaly in southern China becomes obscure due to the nonlinear interaction of the La Niña event and the AO. In this case, there are even weak warm anomalies in the cen- tral-eastern and southwestern parts of China.

Why do the combined effects of the ENSO and the AO in different phases obviously change with each other? Our previous studies found that more stationary planetary waves propagate upward into the stratosphere and bend to the polar region, which may lead to a negative phase of $\mathrm{AO}$ in the stratosphere during an El Niño winter, while a La Niña event favors a stratospheric positive $\mathrm{AO}[32,33]$. If a negative AO month couples with an El Niño winter or a positive AO month couples with a La Niña winter, the response of the stratosphere to the ENSO is favorable for the maintenance of an annular mode. Accordingly, the middle-low 
latitude interaction in East Asia is suppressed, and the winter climate anomalies in East Asia tend to present the linear combination effect of the ENSO and the AO. However, when a positive $\mathrm{AO}$ month couples with an El Niño winter or a negative AO month couples with a La Niña winter, the response of the stratosphere to the ENSO is not helpful in maintaining an annular mode. Hence, the middle-low latitude interaction in East Asia tends to be intensified. The winter climate anomalies in East Asia present the feature of the nonlinear combined effects of the ENSO and the AO. Of course, further research using a high resolution model, which is capable of simulating the stratospheric circulation, is needed to study the detailed physical processes in these combined impacts.

\section{Summary}

The combined effects of the ENSO and the AO on the East Asian winter climate are investigated using 31 winters (1979/1980-2009/2010) worth of NCEP/DOE Reanalysis 2 data and the temperature and precipitation of 160 stations in China. The monthly anomaly of the AO is examined under different backgrounds of El Niño or La Niña events. In view of the cold and dry climate during winter, the temperature anomaly is mainly analyzed with the inclusion of precipitation. The results show that the winter temperature and precipitation in East Asia obviously depends on the configuration of the AO and ENSO phases rather than only one of them.

When an El Niño event couples with a positive AO month or a La Niña event couples with a negative AO month, the temperature anomalies in northern China are mainly influenced by the $\mathrm{AO}$ and the temperature and precipitation anomalies in southern China are dominated by the ENSO. This result indicates the presentations of a dipole pattern with a cold anomaly in the north and a warm anomaly in the south and more rainfall is observed in South China and the southeastern coast area when an El Niño event couples with a negative $\mathrm{AO}$ month. When a La Niña event couples with a positive AO month, the situation tends to be the opposite. Both of these cases can be well explained by the known mechanism regarding how the AO and ENSO influence the winter climate in East Asia. In these cases, a negative (positive) AO is connected with an intensified (weakened) East Asian jet, which leads to more (less) cold surge onsets and a colder (warmer) winter in northern China. The anomalous anticyclone (cyclone) associated with El Niño (La Niña) induces southerly (northerly) to the coastal region of southern China and results in a higher (lower) temperature and more (less) rainfall in those areas. However, the winter climate in most of China, especially southern China, cannot be explained by this mechanism when an El Niño (a La Niña) event coincides with a positive (negative) AO month, although the temperature anomalies in northern China are still dominated by the AO. Southern China is cold rather than warm and receives more rainfall when an El Niño event couples with a positive AO month. When a La Niña couples with a negative AO month, southern China is not very cold and precipitation anomalies are not significant.

The discrepancy between the different combined effects of the ENSO and the AO on the winter climate in East Asia is attributed to the differences in the stratosphere-troposphere interaction and the middle-low latitude interaction in East Asia. The AO tends to be in negative (positive) phase because there is an increased (decreased) propagation of stationary planetary waves into the stratosphere during an El Niño (a La Niña) winter. This pattern is helpful in maintaining an annular mode. Hence, the atmospheric circulation tends to be more zonally symmetric and the interaction between the middle and low latitudes is weaker. In these cases, the impact of the ENSO from the tropics is linearly superimposed on the effect of the AO from the mid-high latitudes over East Asia. This superimposition causes southern China to be warmer (colder) and to receive more (less) rainfall due to El Niño (La Niña), while the northern part is colder (warmer) due to the AO. Nevertheless, the internal processes may be not favorable for an annular mode and induce an intensified middle-low latitude interaction over East Asia when an El Niño (a La Niña) event couples with a positive (negative) AO month. The winter climate anomalies in East Asia present nonlinear combined effects of the ENSO and the AO. That is to say, when a positive AO month couples with an El Niño winter, northern China is dominated by an AO with an anomalous warmth and southern China is cold with more rainfall because of both the ENSO and the AO. In contrast, when a negative $\mathrm{AO}$ month couples with a $\mathrm{La}$ Niña winter, the temperature anomaly is not entirely cold in southern China, although northern China is still dominated by the AO with a cold anomaly. Weak warm anomalies can be found in the central-eastern and southwestern parts of China. The precipitation anomalies are characterized as a dipole pattern with more rainfall in South China and the southeastern coast region and less rainfall in the Yangtze River valley.

It should be noted that the results of this study are robust and not sensitive to the definition of the ENSO because there are several different definitions of ENSO [13,34] (http: //www.cpc.ncep.noaa.gov/products/analysis_monitorin-g/en sostuff/ensoyears.shtml). For example, we used a 5 month running mean Niño 3 index greater than $\pm 0.5^{\circ} \mathrm{C}$ lasting for 6 months as the standard of selecting the ENSO events. The results are nearly the same as those shown in this study. In addition, we performed the analysis with a longer (19682010) dataset from the NCEP/NCAR reanalysis [35] and the results are consistent with the conclusion here. Because the mechanism proposed here only depends on the diagnostic analysis of observations, further confirmation and improvements are needed in the future with a numerical model capable of simulating the stratospheric circulation effectively. 
This work was supported by the National Basic Research Program of Chi$n a(2009$ CB421405) and the National Natural Science Foundation of Chi$n a$ (41025017 and 41230527).

1 Ding Y H. Monsoon Over China. Dordrecht: Kluwer Academic Publishers, 1994. 1-432

2 Huang R H, Zhou L T, Chen W. The progresses of recent studies on the variabilities of the East Asian monsoon and their causes. Adv Atmos Sci, 2003, 20: 55-69

3 Chan J C L, Li C Y. The East Asia winter monsoon. In: Chang C P, ed. East Asian Monsoon. Singapore: World Scientific Publishing Company Incorporated, 2004. 54-106

4 Chen W, Graf H F, Huang R H. The interannual variability of East Asian winter monsoon and its relation to the summer monsoon. Adv Atmos Sci, 2000, 17: 48-60

5 Lau K M, Chang C P. Planetary scale aspects of the winter monsoon and atmospheric teleconnections. In: Chang C P, Krishnamurti T N, eds. Monsoon Meteorology. New York: Oxford University Press, 1987. 161-202

6 Wang L, Chen W, Zhou W. Interannual variations of $500 \mathrm{hPa}$ East Asian trough axis and its influence on the pathway of the East Asian winter monsoon. J Clim, 2009, 22: 600-614

7 Chen W, Li T. Modulation of Northern Hemisphere wintertime stationary planetary wave activity: East Asian climate relationships by the Quasi-Biennial Oscillation. J Geophys Res, 2007, 112: D20120

8 Kang L H, Chen W, Wei K. The interdecadal variation of winter temperature in China and its relation to the anomalies in atmospheric general circulation (in Chinese). Clim Environ Res, 2006, 11: 330-339

9 Chen W, Gu L, Wei K, et al. Studies of the dynamic processes of East Asian monsoon system and the quasi-stationary planetary wave activities (in Chinese). Chin J Atmos Sci, 2008, 32: 950-966

10 Rasmusson E M, Wallace J M. Meteorological aspects of the El Niño/Southern Oscillation. Science, 1983, 222: 1195-1202

$11 \mathrm{Li} \mathrm{C} \mathrm{Y.} \mathrm{Interaction} \mathrm{between} \mathrm{anomalous} \mathrm{winter} \mathrm{monsoon} \mathrm{in} \mathrm{East} \mathrm{Asia}$ and El Niño events. Adv Atmos Sci, 1990, 7: 36-46

12 Zhang R H, Sumi A, Kimoto M. Impact of El Niño on the East Asian monsoon: A diagnostic study of the 86/87 and 91/92 events. J Meteorol Soc Jpn, 1996, 74: 49-62

13 Wang B, Wu R G, Fu X H. Pacific-East Asian teleconnection: How does ENSO affect east Asian climate? J Clim, 2000, 13: 1517-1536

14 Chen W. Impacts of El Niño and La Niña on the cycle of the East Asian winter and summer monsoon (in Chinese). Chin J Atmos Sci, 2002, 26: 595-610

15 Gong D Y, Wang S W, Zhu J H. East Asian winter monsoon and Arctic oscillation. Geophys Res Lett, 2001, 28: 2073-2076

16 Wu B Y, Wang J. Winter Arctic Oscillation, Siberian High and East Asian winter monsoon. Geophys Res Lett, 2002, 29: 1897

17 Jeong J H, Ho C H. Changes in occurrence of cold surges over east Asia in association with Arctic Oscillation. Geophys Res Lett, 2005, 32: L14704
18 Chen W, Yang S, Huang R H. Relationship between stationary planetary wave activity and the East Asian winter monsoon. J Geophys Res, 2005, 110: D14110

19 Gong D Y, Zhu J H, Wang S W. Significant relationship between spring $\mathrm{AO}$ and the summer rainfall along the Yangtze River (in Chinese). Chin Sci Bull (Chin Ver), 2002, 47: 546-549

20 Thompson D W J, Wallace J M. The Arctic Oscillation signature in the wintertime geopotential height and temperature fields. Geophys Res Lett, 1998, 25: 1297-1300

21 Baldwin M P, Dunkerton T J. Propagation of the Arctic Oscillation from the stratosphere to the troposphere. J Geophys Res, 1999, 104: 30937-30946

22 Suo L L, Tan B K, Huang J Y. Further exploration on causes of temperature anomalies associated with the abnormal northern annular mode. Chin Sci Bull, 2009, 54: 2101-2106

23 Chen W, Kang L H. Linkage between the Arctic Oscillation and winter climate over East Asia on the interannual timescale: Roles of quasi-stationary planetary waves (in Chinese). Chin J Atmos Sci, 2006, 30: 863-870

24 Chen W, Zhou Q. Modulation of the Arctic Oscillation and the East Asian winter climate relationships by the 11-year solar cycle. Adv Atmos Sci, 2012, 29: 217-226

25 Wang L, Chen W. How well do existing indices measure the strength of the East Asian winter monsoon? Adv Atmos Sci, 2010, 27: 855870

26 Wen M, Yang S, Kumar A, et al. An analysis of the large-scale climate anomalies associated with the snowstorms affecting China in January 2008. Mon Weather Rev, 2009, 137: 1111-1131

27 Wang L, Chen W. Downward Arctic Oscillation signal associated with moderate weak stratospheric polar vortex and the cold December 2009. Geophys Res Lett, 2010, 37: L09707

28 Kanamitsu M, Ebisuzaki W, Woollen J, et al. NCEP-DEO AMIP-II Reanalysis (R-2). Bull Amer Meteorol Soc, 2002, 83: 1631-1644

29 Feng J, Wang L, Chen W, et al. Different impacts of two types of Pacific Ocean warming on Southeast Asian rainfall during boreal winter. J Geophys Res, 2010, 115: D24122

30 Zhou L T, Tam C, Zhou W, et al. Influence of South China Sea SST and ENSO on winter rainfall over south China. Adv Atmos Sci, 2010, 27: 832-844

31 Wang L, Feng J. Two major modes of the wintertime precipitation over China (in Chinese). Chin J Atmos Sci, 2011, 35: 1105-1116

32 Chen W, Graf H F, Takahashi M. Observed interannual oscillations of planetary wave forcing in the Northern Hemisphere winter. Geophys Res Lett, 2002, 29: 2073

33 Lan X Q, Chen W, Wang L. Quasi-stationary planetary wave-mean flow interactions in the Northern Hemisphere stratosphere and their responses to ENSO events. Sci China Earth Sci, 2012, 55: 405-417

34 Trenberth K. The definition of El Niño. Bull Amer Meteorol Soc, 1997, 78: 2771-2777

35 Kalnay E, Kanamitsu M, Kistler R, et al. The NCEP/NCAR 40-year reanalysis project. Bull Amer Meteorol Soc, 1996, 77: 437-471

Open Access This article is distributed under the terms of the Creative Commons Attribution License which permits any use, distribution, and reproduction in any medium, provided the original author(s) and source are credited 